\title{
Correlation of Carotid Artery Pathologies with White Matter Diseases in Geriatric Patients
}

\author{
Meena GL*, Khizer Razak and Surbhi Gupta \\ Department of Radiodiagnosis, Sardar Patel Medical College, India \\ *Corresponding author: Meena GL, Senior Professor \& Head, Department of Radiodiagnosis, Sardar Patel Medical College, Bikaner, Rajasthan 334003, \\ India
}

Submission: 㯺 November 10, 2017; Published: 㭗 December 12, 2017

\begin{abstract}
Aims \& objectives: We aim to evaluate the correlation between the spectrum of white matter diseases and carotid arterial system; to elucidate the pathophysiology and risk factors of white matter diseases.

Materials \& methods: In this study conducted during 2016-2017, 32 patients were referred to hospital Radiology Department, P.B.M. hospital, Bikaner, Rajasthan. The age range chosen was of 60-88 years as there are increased signals on T2-weighted MR images, indicating periventricular white matter diseases, were examined by duplex Doppler evaluation of the carotid arterial system. Hitachi Prosound Aloka Alpha A7 device a 7.5-15 MHz probe was used. The control group comprised 36 patients which were of the same age as that of the patients chosen between 60-88 years. IMT (intimomedial thickness) complex of the carotid arteries was evaluated to assess the degree of carotid stenosis.

Conclusion: As per the results obtained in our study with patients of white matter diseases of geriatric age group, there were associated increased thicknening of the intimo-medial layer of the arterial tree. These results are consistent with the hypothesis that the ischemic process lead to the development of white matter diseases. This hypothesis also shows that, white matter diseases occurs following reactive gliosis secondary to chronic ischemia, induced by plugging of small arteries supplying the white matter region.
\end{abstract}

Keywords: White matter diseases; Carotid; Intima; MR; Imaging

\section{Introduction}

White matter diseases are associated with increased signals in the white matter tract on T2-weighted magnetic resonance imaging (MRI) images in geriatric patients [1]. White matter increased signals are known to portray a correlation between age, senile hypertension, diabetes mellitusetc, [2-5]. However, the genetic premonition is better associated with these white matter diseases. Studies, related to the demographics and epidemiology elucidate the link between memory, psychosomatic deterioration and imbalance of geriatric population who have white matter hyper intensities. Senile individuals have proposed a lucid correlation between decreased compos mentis and increased signals on white matter tracts on T2 weighted images on MR [6]. The presence of such signals may also pose a risk factor for stroke $[7,8]$. Pathogenesis of hyper intensities seen on MRI is not fully elucidated. Small arterial diseases appear to be the chief\& principal etiological insult of such hyper intensities [9], also disruption of the blood cerebral barrier may implicate in the disease process [10]. However, an intricate association with the presence of arteriosclerosis in the medium sized arteries, the white matter infarcts and white matter changes are well known and proven [8,11-15]. Any large vessel disease which is prone for the necrosis of white matter, compromise of blood flow could be an indirect insult in the development of such hyper intensities.

\section{Materials \& Methods}

In this study conducted during 2016-2017, 32 patients were referred to hospital Radiology Department, P.B.M. hospital, Bikaner, Rajasthan [16]. The age range chosen was of 60-88 years as there are increased signals on T2-weighted MR images, indicating per ventricular white matter diseases, were examined by duplex Doppler evaluation of the carotid arterial system [17]. HITACHI PROSOUND ALOKA ALPHA A 7 device a $7.5-15 \mathrm{MHz}$ probe was used. The control group comprised 36 patients which were of the same age as that of the patients chosen between $60-88$ years. IMT (intimo-medial thickness) complex of the carotid arteries was evaluated to assess the degree of carotid stenosis (Figure 1).

Plaques noted in carotid vessels were illustrated by duplex Doppler study (Bock-Lusby Classification). Type I plaque is seen as hypoechoic plaques, Type II plaques are predominantly hypoechoic, but also containing specks of hyperechoicareas, Type III plaques have a predominant hyperechoic component \&the more calcified are characterized as Type IV [18,19]. 


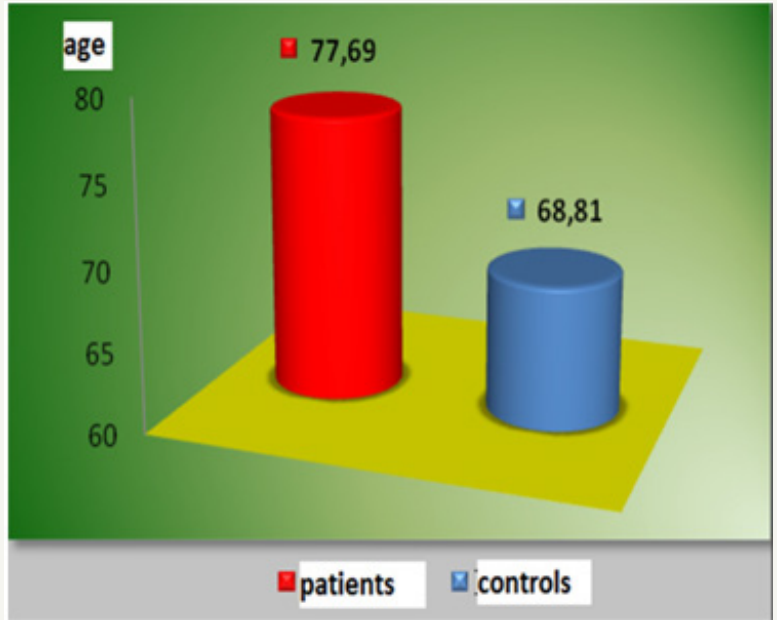

Figure 1: Mean age of the patient group and controls.

\section{Result}

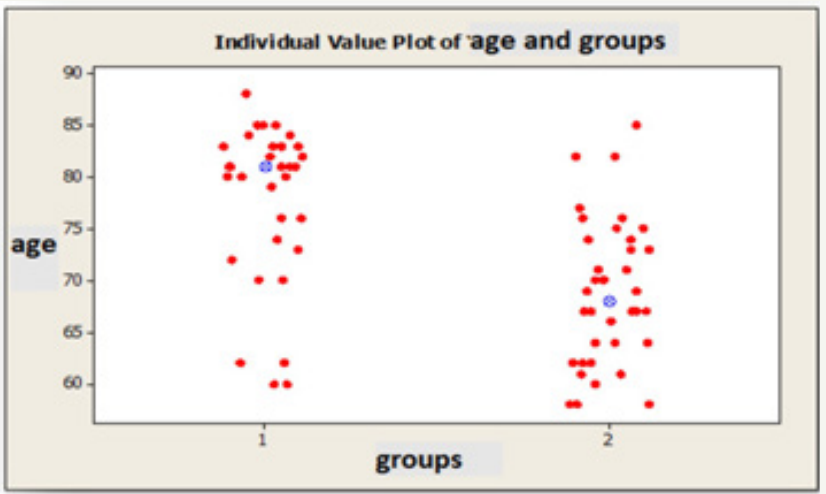

Figure 2: A scatter plot of age(s) and groups of the control \& patients.

Table 1: shows the age criterion which is statistically significant.

\begin{tabular}{|c|c|c|c|c|c|}
\hline Age & N & Mean \pm S.D & Median & Minimum & Maximum \\
\hline Patients & 32 & $77.69 \pm 7.79$ & 81 & 60 & 88 \\
\hline Control & 36 & $68.81 \pm 7.05$ & 68 & 58 & 85 \\
\hline Total & 68 & $72.99 \pm 8.60$ & 73.5 & 58 & 88 \\
\hline
\end{tabular}

A total of 32 white matter disease patients between the ages of 60-88 years, 11 males, 21 females, and in the same age range 36 people who had no such white matter diseases: a total of 15 men and 21 women were evaluated with duplex Doppler study for atherosclerotic intima-medial thicknesses, severity of stenosis and characteristics of the plaques (Figure 2). These results were statistically analyzed using Mann Whitney U test, Fisher's exact chi-square test and the data with Pearson's test (Table 1). There are statistically significant differences between the groups in terms of age $\left(\mathrm{p}=0.001^{*}\right)$. Patients with white matter diseases are elder than the control subjects. Among the two groups Intimo-medial thickness shows a statistically significant difference $\left(\mathrm{p}=0.001^{*}\right)$.
Intimo-medial thickness of the carotid arterial tree in the patient group is higher than in the control group (Table 2).

Table 2: Shows the correlation between the intimo-medial thickness criterion and the patients with white matter diseases, which is statistically significant $\left(p=0.001^{*}\right)$.

\begin{tabular}{|c|c|c|c|c|c|}
\hline $\begin{array}{c}\text { Intimo- } \\
\text { Medial } \\
\text { Thickness }\end{array}$ & $\mathbf{N}$ & Mean \pm S.D & Median & Minimum & Maximum \\
\hline Patients & 32 & $1.08 \pm 0.11$ & 1.1 & 0.8 & 1.3 \\
\hline Control & 36 & $0.88 \pm 0.8$ & 0.8 & 0.8 & 1.1 \\
\hline Total & 68 & $0.88 \pm 1.0$ & 1 & 0.8 & 1.3 \\
\hline
\end{tabular}

\section{Conclusion}

As per the results obtained in our study with patients of white matter diseases of geriatric age group, there were associated increased thicknening of the intimo-medial layer of the arterial tree [20]. These results are consistent with the hypothesis that the ischemic process lead to the development of white matter diseases [21-23]. This hypothesis also shows that, white matter diseases occurs following reactive gliosis secondary to chronic ischemia, induced by plugging of small arteries supplying the white matter region. White matter signals are associated with significant age related morbidity and mortality. Periventricular increased white matter signals accounts for the bulk of these signals observed in this population of aging women [24]. Increased age, BMI (body mass index) and internal carotid arterial (ICA) resistance to flow (pulsatility index) were found to be strongly and significantly predictive of such periventricular signals development [25].

Age and BMI were the only significant risk factors for the development of deep white matter increased signals [26]. Framingham cardiovascular risk score was not a significant risk factor for the development of WMH in this group (Figure 3). These regression equations need to be tested on an independent data set to confirm the predictive ability of age, BMI and the ICA pulsatility index [27]. The ICA pulsatility index measured by duplex ultrasound may prove to be an important predictive variable in determining those at risk of increased white matter signals and its sequelae. The ICA pulsatility index may be an ideal target for therapeutics aimed at reducing the progression of such hyper intensities [28].

Our data suggest a statistically significant correlation between white matter diseases and the age factor, atherosclerosis, carotid artery pathologies including plaques and stenosis.

\section{References}

1. Hachinski VC, Potter P, Merskey H (1987) Leukoaraiosis. Arch Neurol 44(1): 21-23.

2. Pantoni L, Garcia JH (1997) Pathogenesis of leukoaraiosis: a review. Stroke 28(3): 652-659.

3. Murray AD, Staff RT, Shenkin SD, Deary IJ, Starr JM, et al. (2005) Brain white matter hyperintensities: relative importance of vascular risk factors in nondemented elderly people. Radiology 237(1): 251-257.

4. Janota I, Mirsen TR, Hachinski VC, Lee DH, Merskey H, et al. (1989) 
Neuropathologic correlates of leuko-araiosis. Arch Neurol 46(10): 1124 1128.

5. Ginsberg MD, Hedley WET, Richardson EP (1976) Hypoxic-ischemic leukoencephalopathy in man. Arch Neurol 33(1): 5-14.

6. Garde E, Mortensen EL, Krabbe K, Rostrup E, Larsson HB, et al. (2000) Relation between age related decline in intelligence and cerebral whitematter hyperintensities in healthy octogenarians: a longitudinal study. Lancet 356(9230): 628- 634.

7. Streifler JY, Eliasziw M, Benavente OR, Alamowitch S, Fox AJ, et al. (2003) Development and progression of leukoaraiosis in patients with brain ischemia and carotid artery disease. Stroke 34(8): 1913-1916.

8. Fu JH, Lu CZ, Hong Z, Dong Q Luo Y, et al. (2005) Extent of white matter lesions is related to acute subcortical infarcts and predicts further stroke risk in patients with first ever ischaemic stroke. J Neurol Neurosurg Psychiatry 76(6): 793-796.

9. Pantoni L, Garcia JH (1995) The significance of cerebral white matter abnormalities 100 years after Binswanger's report: a review. Stroke 26(7): 1293-1301.

10. Wardlaw JM, Sandercock PA, Dennis MS, Starr J (2003) Is breakdown of the blood-brain barrier responsible for lacunar stroke, leukoaraiosis, and dementia? Stroke 34(3): 806-812.

11. De Leeuw FE, de Groot JC, Bots ML, Witteman JC, Oudkerk M, et al. (2000) Carotid atherosclerosis and cerebral white matter lesions in a population based magnetic resonance imaging study. J Neurol 247(4): 291-296.

12. Yamauchi H, Fukuyama H, Nagahama Y, Shiozaki T, Nishizawa S, et al (1999) Brain arteriolosclerosis and hemodynamic disturbance may induce leukoaraiosis. Neurology 53(8): 1833-1838.

13. Lee PH, Oh SH, Bang OY, Joo IS, Huh K, et al. (2005) Pathogenesis of deep white matter medullary infarcts: a diffusion weighted magnetic resonance imaging study. J Neurol Neurosurg Psychiatry 76(12): 16591663.

14. Yonemura K, Kimura K, Minematsu K, Uchino M, Yamaguchi T, et al. (2002) Small centrum ovale infarcts on diffusion-weighted magnetic resonance imaging. Stroke 33: 1541-1544.

15. Altaf N, Daniels L, Morgan PS, Lowe J, Gladman J, et al.(2006) Cerebral white matter hyperintense lesions are associated with unstable carotid plaques. Eur J Vasc Endovasc Surg 31(1): 8-13.
16. Hachinski VC, Potter P, Merskey H (1987) Leuko-araiosis. Arch Neurol 44(1): 21-23

17. Kertesz A, Polk M, Carr T (1990) Cognition and white matter changes on magnetic resonance imaging in dementia. Arch Neurol 47(4): 387-391.

18. Scoutt LM, Zawin ML, Taylor KJ (1990) Doppler US. Part II. Clinical applications. Radiology 174(2): 309-319.

19. Inzitari D, Mascalchi M, Giordano GP, Marini P, Sita D, et al. (1989) Histopathological correlates of leukoaraiosis in patients with ischemic stroke. Eur Neurol 46: 23-26.

20. Henon H, Vroylandt P, Durieu I, Pasquier F, Leys D, et al. (2003) Leukoaraiosis more than dementia is a predictor of stroke recurrence. Stroke 34(12): 2935-2940.

21. Andrei VA (2004) Cerebrovascular Ultrasound in Stroke Prevention and Treatment. RVT 45: 4-6.

22. Altaf N, Daniels L, Morgan PS, Lowe J, Gladman J, et al. (2006) Cerebral white matter hyperintense lesions are associated with unstable carotid plaques. Eur J Vasc Endovasc Surg 31(1): 8-13.

23. Fazekas F, Kleinert R, Offenbacher H, Schmidt R, Kleinert G, et al. (1993) Pathologic correlates of incidental MRI white matter signal hyperintensities. Neurology 43(9): 1683-1689.

24. Zhu YC, Dufouil C, Tzourio C, Chabriat H (2011) Silent brain infarcts: a review of MRI diagnostic criteria. Stroke 42(4): 1140-1145.

25. Wardlaw JM, Smith EE, Biessels GJ, Cordonnier C, Fazekas F, et al. (2013) Neuroimaging standards for research into small vessel disease and its contribution to ageing and neurodegeneration. Lancet Neurol 12(8): 822-838.

26. Vermeer SE, Koudstaal PJ, Oudkerk M, Hofman A, Breteler MM, et al. (2002) Prevalence and risk factors of silent brain infarcts in the population-based Rotterdam Scan Study. Stroke 33(1): 21-25.

27. Van Dijk EJ, Breteler M, Schmidt R, Berger K, Nilsson LG, et al. (2004) The association between blood pressure, hypertension and cerebral white matter lesions. Stroke 44(5): 625-630.

28. Adams HH, Margherita C, Benjamin FV, Daniel Bos, Van Der LA, et al. (2013) Rating Method for Dilated Virchow-Robin Spaces on Magnetic Resonance Imaging. Stroke 44(6): 1732-1735. 